Dicle Tıp Dergisi / Dicle Med J (2019) 46 (2) : 283 - 288

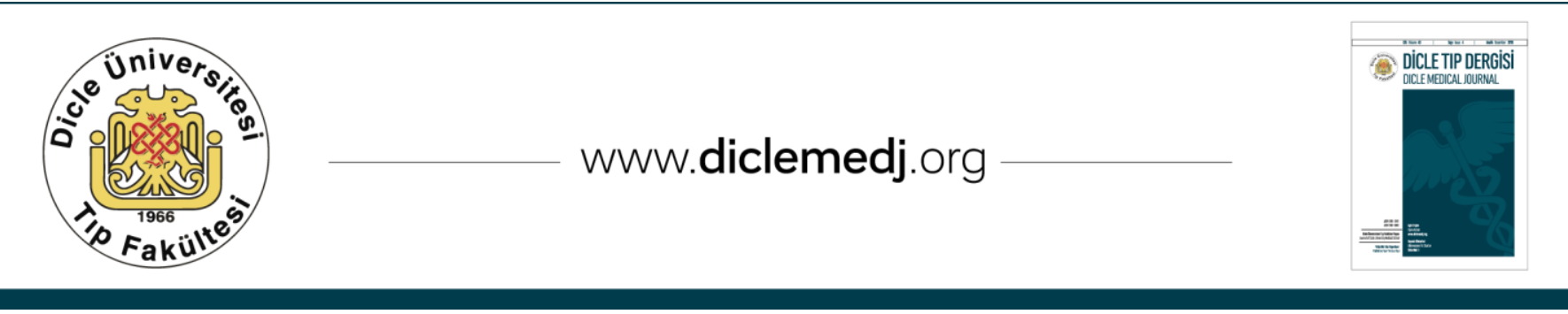

Özgün Araștırma / Original Article

\title{
Çocuk Kardiyoloji Polikliniğine Göğüs Ağrısı Şikayeti ile Başvuran Hastaların Etyolojik Değerlendirilmesi
}

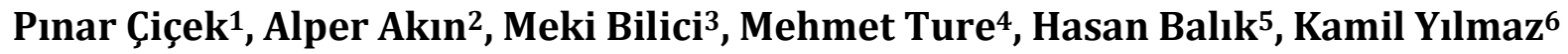 \\ 1 Dicle Üniversitesi Tıp Fakültesi Çocuk Sağlığı ve Hastalıkları Anabilim Dalı, Diyarbakır, Türkiye ORCID: 0000-0002-3658-9617 \\ 2 Dicle Üniversitesi Tıp Fakültesi Çocuk Kardiyolojisi Bilim Dal, Diyarbakır, Türkiye ORCID: 0000-0003-1587-9559 \\ 3 Dicle Üniversitesi Tıp Fakültesi Cocuk Kardiyolojisi Bilim Dal, Diyarbakır, Türkiye ORCID: 0000-0001-8316-7102 \\ 4 Dicle Üniversitesi Tıp Fakültesi Çocuk Kardiyolojisi Bilim Dall, Diyarbakır, Türkiye ORCID: 0000-0001-8780-8122 \\ 5 Dicle Üniversitesi Tıp Fakültesi Çocuk Kardiyolojisi Bilim Dall, Diyarbakır, Türkiye ORCID: 0000-0002-3373-1585 \\ 6 Dicle Üniversitesi Tıp Fakültesi Çocuk Sağhı̆̆ı ve Hastalıkları Anabilim Dalı, Diyarbakır, Türkiye ORCID: 0000-0001-5137-0501
}

Geliş: 31.07.2018; Revizyon: 02.04.2019; Kabul Tarihi: 03.05.2019

Öz

Amaç: Gögüs ağrısı, çocuk kardiyoloji polikliniklerine sık başvuru semptomlarındandır. Hastaların önemli bir bölümünde iyi bir anamnez ve fizik muayene ile etyoloji aydınlatılabilir. Hayatı tehdit eden göğüs ağrısı nedenlerinin sıklığı azdır. Bu çalışmada çocuklarda göğüs ağrısı nedenleri araştırılmış ve ayırıcı tanıda göz önünde bulundurulması gereken patolojilere dikkat çekilmiştir.

Yöntemler: Çalışmaya Çocuk Kardiyoloji Polikliniğine 1 Ekim 2017- 1 Aralık 2017 tarihleri arasında göğüs ağrısı şikayeti ile başvuran 134 hasta alındı. Hastaların dosya kayıtlarından ayrıntılı anamnezleri ve detaylı fizik muayane kayıtları incelendi ve etyolojiye yönelik incelemeler değerlendirildi.

Bulgular: Hastaların yaşı $12,7 \pm 3,2$ yıl (5-18 yaş) olup 78‘i $(\% 58,2)$ erkekti. Göğüs ağrısı yakınmasının süresi ortalama 5,5 ay (1 gün-4 yıl), atakların süresi 1 saniye ile 3 saat arasında değişmekteydi. Hastaların \%29'unda idiyopatik nedenli göğüs ağrısı düşünüldü. Göğüs ağrısının diğer nedenleri sırasıyla şunlardı: Kas-iskelet sistemi kaynaklı (\%26), psikojenik $(\% 12,6)$, sindirim sistemi patolojileri $(\% 8,9)$, astım bronşiyale $(\% 6,7)$, üst solunum yolu enfeksiyonu $(\% 5,9)$, mitral kapak prolapsusu $(\% 3,7)$, miyokardit $(\% 2,2)$, ailevi akdeniz ateşi $(\% 1,4)$ ve birer hastada nefrolityazis, gögüs travması, perikardit, gögüs deformitesi saptandı.

Sonuç: Göğüs ağrısı adolesan dönemde daha fazla görülür. Gögüs ağrısını değerlendirirken anamnez ve fizik muayeneye önem verilmeli ve organik neden düşünülen hastalarda ileri incelemeler yapılmalıdır. Kardiyak kaynaklı gögüs ağrısı sıklığı azdır ve kardiyak patoloji düşünülen hastalarda çocuk kardiyoloji uzmanına danışılmalıdır.

Anahtar kelimeler: Göğüs ağrısı, çocuk, kardiyak.

DOI: $10.5798 /$ dicletip

Yazışma Adresi / Correspondence: Alper Akın, Dicle Üniversitesi Tıp Fakültesi Çocuk Kardiyolojisi Bilim Dall, Diyarbakır, Türkiye e-mail: alperakin1@hotmail.com 


\title{
Etiological Evaluation of the Patients Attending to the Pediatric Cardiology Clinic with Chest Pain
}

\begin{abstract}
Objective: Chest pain is a frequent symptom of pediatric cardiology outpatient clinics. A significant part of the patients' etiology can be elucidated with a good history and physical examination. The cause of life-threatening chest pain is less frequent. In this study, the causes of chestpain in children were investigated and attention was paid to pathologies that should be considered in differential diagnosis.

Methods: A total of 134 patients who were admitted to the Pediatric Cardiology Clinic between 1 October 2017 and 1 December 2017 with complaints of chest pain were studied. The detailed anamnesis and detailed physical examination records of the patients were reviewed and evaluated for etiology.

Results: The age of the patients was12.7 \pm 3.2 years (5-18 years) and 78 patients (58.2\%) were male. The average duration of chest pain was 5,5 months ( 1 day-to 4 years), and the duration of attacks ranged from 1 second to 3 hours. Idiopathic chest pain was considered in $29 \%$ of the patients. Other causes of chest pain were: musculoskeletal (26\%), psychogenic (12.6\%), digestive system pathologies (8.9\%), asthma bronchiale (6.7\%), upper respiratory tract infection (5.9\%), mitral valve prolapse (3.7\%), myocarditis (2.2\%), familial mediterranean fever (1.4\%), nephrolithiasis $(0.7 \%)$, chesttrauma (0.7\%), pericarditis $(0.7 \%)$ and chest deformity $(0.7 \%)$, respectively.

Conclusion: Chest pain is more common in adolescence. When assessing chest pain, anamnesis and physical examination should be emphasized and further studies should be done in patients thought to be organic causes. Cardiac-induced chest pain is less frequent. The pediatric cardiologist should be consulted when cardiac pathology is suspected.
\end{abstract}

Keywords: Chest pain, child, cardiac.

\section{GíRiş}

Göğüs ağrısı, çocuklarda polikliniklere sık başvuru şikayetlerindendir ve adolesanlarda görülme sıklı̆̆ daha fazladır. Çocuklarda göğüs ağrısının en sık nedenleri idiyopatik göğüs ağrısı, kas iskelet sistemi patolojileri, solunumsal ve gastrointestinal sistem patolojilerdir. Kardiyak nedenler daha nadir görülmektedir ve sıklı̆̆l genellikle \%5'in altındadır. Kardiyak nedenler az olmasına rağmen çocuklardaki göğüs ağrlları gerek hasta ve ailesi gerekse klinisyenler için bir endişe kaynağıdır ${ }^{1,2,3}$.

İyi bir anamnez ve fizik muayene sonrası çoğu hastada ileri incelemelere gerek kalmadan tanı konulabilmektedir. Ancak organik nedenlerin dışlanamadığı, özellikle kardiyak nedenli göğüs ağrısı düşünülen hastalarda elektrokardiyografi, ekokardiyografi ve hatta kardiyak kateterizasyon ve anjiyografi gibi daha ileri incelemeler de gerekebilir. $\mathrm{Bu}$ nedenle klinisyenlerin göğüs ağrısı nedeni ile başvuran çocuklarda olası nedenleri ve bu nedenlere işaret eden semptomları iyi bilmesi gerekmektedir. Bu çalışmada çocuk kardiyoloji polikliniğine gögüs ağrısı şikayeti ile başvuran çocuklarda göğüs ağrısının nedenleri değerlendirilmiş ve diğer bölgelerde yapılmış çalışmalar ile karşılaştırılmıştır. Böylece ayırıcı tanıda anamnez ve fizik muayenenin önemine dikkat çekilmiş; başta nadir görülen kardiyak patolojiler olmak üzere bölge verileri elde edilmiștir ${ }^{1-6}$.

\section{YÖNTEMLER}

Çalışmaya Dicle Üniversitesi Tıp Fakültesi Çocuk Kardiyoloji Polikliniğine Ekim 2017 ile Aralık 2017 tarihleri arasında başvuran hastalardan göğüs ağrısı şikayeti olanlar dahil edildi. Çalışma dönemi boyunca göğüs ağrısı şikayeti ile çocuk kardiyoloji polikliniğine 
başvuran ve yaşları 5-18 yaş arasında değișen 78'i erkek, 56'sı kız olmak üzere toplam 134 hastanın dosya kayıtlarından ayrıntılı anamnezleri, detaylı fizik muayane kayıtları incelendi ve etyolojiye yönelik incelemeler değerlendirildi.

Verilerin elde edilmesinde göğüs ağrısı şikayeti ile polikliniğe başvuran hastalarımızda kullandığımız "göğüs ağrısı sorgulama ve değerlendirme formu" bilgilerinden de yararlanıldı. Bu formda hasta bilgileri, yaşı, antropometrik ölçüleri, şikayetleri, şikayetlerin süresi ve sıklığı, tetikleyen faktörler, eşlik eden semptomlar, fizik muayene bulguları ve laboratuvar bulguları, varsa danıșılan bölüm ve hastanın nihai tanısı yer almaktadır. Ağrının ilk ortaya çıktığı andan itibaren hastaların hastaneye başvurana kadar geçirdikleri süre, ağrının sıklığı ve süresi, niteliği, lokalizasyonu, varsa yayılımı; ağrının eforla, solunumla ve beslenme ile ilişkisi; varsa eşlik eden semptomlar, aile öyküsü, ağrıya neden olabilecek psikojenik faktörler ve travma öyküsü sorgulandı. Psikojenik sorunların bazen gögüs ağrısının bir sonucu da olabileceği düşünülerek sadece tetikleyici psikojenik faktörden sonra göğüs ağrısı başlayan ve başka bir neden saptanmayan hastalarda psikojenik göğüs ağrısı düşünüldü; bu hastalar ayrıca çocuk psikiyatri uzmanına da yönlendirildi. On iki derivasyonlu elektrokardiyografi (EKG) ve transtorasik ekokardiyografik (EKO) kayıtları değerlendirildi. İleri inceleme yapılmış olan hastalarda varsa direkt göğüs grafisi, tam kan sayımı, karaciğer ve böbrek fonksiyonları ve kardiyak enzimleri; ayrıca efor testi ve 24 saat Holter monitorizasyonu kayıtları incelendi. Uygun görülen hastalarda çocuk psikiyatrisi, çocuk göğüs hastalıkları ve çocuk hastalıklarına ait diğer bölümlerin de görüşü alınmıştır. Çalışma için Dicle Üniversitesi Tıp Fakültesi Girișimsel olmayan Etik Kurulu'ndan (06.06.2018/231) onay alındı.

Çalışmada toplanan verilerin analizi, istatistiksel yazllım paketi SPSS 23 (Statistical
Package for the Social Sciences - IBM $\AA$, Chicago, IL, USA) istatistik programı kullanılarak yapıldı. Çalışmada tanımlayıcı istatistik yöntemleri kullanılmış olup veriler sayı ve yüzde olarak ifade edilmiştir.

\section{BULGULAR}

Çalışmaya yaşları 5-18 yıl arasında olan 134 olgu alındı. Hastaların yaş ortalaması $12.7 \pm 3.2$ yıl olup 78'i $(\% 58,2)$ erkekti. Hastaların vücut ağırlığı ortalaması $44.7 \pm 15.1 \mathrm{~kg}$, vücut kitle indeksi (BMI) 18.7 \pm 4.1 , kalp tepe atımları $86 \pm 16.0 /$ dakika, tam kanda beyaz küre (WBC) $9.52 \pm 4.2 \mathrm{~K} / \mathrm{uL}$, hemoglobin $13.8 \pm 1.1 \mathrm{~g} / \mathrm{dl}$ olarak saptandı. Üç hastada kardiyak enzimler (troponin I ve CK-MB) normal düzeylerin üstünde olup bu üç hasta da diğer klinik, laboratuvar ve ekokardiyografik bulguları ile birlikte değerlendirildiğinde miyokardit tanısı almıştır. Göğüs ağrısı yakınmasının süresi ortalama 5.5 ay (1 gün-4 yıl), atakların süresi 1 saniye ile 3 saat arasında değişmekteydi.

Etyolojik değerlendirme sonucunda ağrının diğer nedenleri dışlandıktan sonra hastaların \%29'unda (39 hasta) idiyopatik, \%12,6'sında ise (17 hasta) psikojenik nedenli göğüs ağrısı düşünüldü. Göğüs ağrısının diğer nedenleri sırasıyla hastaların \%26'sında (n:35) kasiskelet sistemi (kostokondrit, nonspesifik miyalji, prekordial yakalama sendromu), \%8,9'unda (n:12) sindirim sistemi patolojileri (gastroözofageal reflü, gastrit, özofajit), \%6,7'sinde (n:9) astım, \%5,9'unda (n:8) üst solunum yolu enfeksiyonu olarak saptand. Hastaların \%6,7'sinde (n:9) gögüs ağrısı nedeni kardiyak patolojilere bağlandı ( 5 hasta mitral kapak prolapsusu, 3 hasta miyokardit, 1 hasta perikardit). Hastaların \%1,4'ünde (n:2) ailevi akdeniz ateşi (FMF), birer $(0,7)$ hastada ise nefrolityazis, göğüs travması, göğüs deformitesi saptandı (Tablo 1). 
Tablo 1: Göğüs ağrısı şikayeti ile başvuran hastaların etyolojik değerlendirmesi

\begin{tabular}{|lll|}
\hline NEDENLER & $\%$ & $\mathbf{n}$ \\
Idiyopatik & 29 & 39 \\
Kas-iskelet sistemi & 26 & 35 \\
Psikojenik & 12,6 & 17 \\
Sindirim sistemi patolojileri & 8,9 & 12 \\
Astım Bronşiyale & 6,7 & 9 \\
Kardiyak & 6,7 & 9 \\
\multicolumn{1}{|c|}{ Mitral kapak prolapsusu } & 3,7 & 5 \\
\multicolumn{1}{|c|}{ Perikardit } & 2,2 & 3 \\
Üst solunum yolu enfeksiyonu & 0,7 & 1 \\
Ailevi Akdeniz Ateşi & 5,9 & 8 \\
Nefrolityazis & 1,4 & 2 \\
Göğüs travması & 0,7 & 1 \\
Göğüs deformitesi & 0,7 & 1 \\
Toplam & 0,7 & 1 \\
\hline
\end{tabular}

\section{TARTIŞMA}

Göğüs ağrısı, çocukluk dönemindeki poliklinik başvurularında önemli bir yer tutmaktadır. Organik nedenler nadirdir ve doğru bir değerlendirme ile hastaların büyük bölümünde tanı konulabilmektedir. Göğüs ağrısı yakınması özellikle adölesan dönemde sık karşımıza çlkmakta olup, en sık 12-14 yaşları arasında görülmektedir ${ }^{7}$. Çalışmamızda benzer şekilde hastaların büyük bölümü adölesan dönemde olup yaş ortalaması 12,7 \pm 3,2 (5-18 yaş) yıldı. Çocuk yaş grubunda erkeklerde kızlara oranla gögüs ağrısı sıklığının biraz daha fazla olduğu bildirilmiştir8,9. Çalışmamızda da literatüre benzer şekilde hastaların çoğunluğu erkekti.

Çalıșmamızda göğüs ağrısı ile başvuran hastaların \%29'unda gögüs ağrısına neden olabilecek bir patoloji saptanamadı ve bu hastalar idiyopatik gögüs ağrısı olarak değerlendirildi. Literatürde de \%20-45 hastada gögüs ağrısının nedeninin saptanamadığı ve idiyopatik olarak değerlendirildiği bildirilmiştiri,10,11. İyi bir anamnez alınması ve ayrıntılı fizik muayene yapılması, gereken durumlarda laboratuvar yöntemlerinin etkili kullanılması durumunda idiyopatik nedenlerin sıklığının da azalması beklenmektedir. Nedenin belirlenebildiği göğüs ağrılarında en sık neden başta kostokondrit olmak üzere kas-iskelet sistemine ilişkin nedenlerdir ${ }^{1,12,13}$. Ağrının solunumla ya da belirli aktivitelerle artması, tetikleyici ortadan kaldırıldığında ağrının sonlanması ya da fizik muayenede başka anormal bulgunun tespit edilmemesi tanida yardımcıdır ${ }^{2}$ Çalıșmamızda idiyopatik nedenlerden sonra en sık göğüs ağrısı nedeni kas-iskelet kaynaklı göğüs ağrısı olarak saptanmıştır.

Diğer nedenler incelendiğinde psikojenik nedenler, gastrointestinal sisteme ait nedenler, solunum sistemine ait nedenler ve daha az sıklıkta kardiyak nedenleri görmekteyiz ${ }^{1,2,14}$. Psikojenik nedenler özellikle adölesan yaş grubunda sık olarak karşımıza çıkmakta olup ağrı değişken ve karakteristik özellik göstermeyen vasıftadır. Genellikle bir stres faktörü ile tetiklenir ${ }^{15}$. Bu grupta tetikleyici neden genellikle panik atak, depresyon veya hiperventilasyon sendromudur ${ }^{2}$. Ülkemizde gögüs ağrısı ile başvuran çocuklarda \%3-10,7 oranında psikojenik faktörler bildirilmiștir ${ }^{1,13}$. Çalışmamızda psikojenik nedenli göğüs ağrısı sıklığı bu değerlerden biraz yüksek saptanmıştır. Çalışmanın yapıldığı bölgedeki sosyoekonomik sorunlar ve hızlı şehirleşmenin buna katkıda bulunduğunu düşünüyoruz.

Solunum sistemine ait nedenler incelendiğinde astım en sık görülen solunum sistemi kaynaklı göğüs ağrısı nedenidir ve bunlarda göğüs ağrısı sıklıkla egzersiz sonrası ortaya çıkar. Ayrıca solunum yolu enfeksiyonları da gögüs ağrısına neden olabilirler ${ }^{2,13}$. Çalışmamızda solunum sistemine ait nedenler üst solunum yolu enfeksiyonu ve astım olup (toplam \%12,6) bunların yarısından fazlasinı $(\% 52,9)$ astım 
oluşturmaktadır. Sert A. ve $\operatorname{arkadaşları}^{1}$ çocuklarda solunum sistemi kaynaklı gögüs ağrısı sıklığının \%6,6 olduğunu, bunların da $\% 28$ 'inde astım olduğunu bildirmişlerdir. Öztürk K.13 ve arkadaşları ise tüm gögüs ağrısı nedenlerinin $\% 5,1^{\prime}$ 'inin solunum sistemi kaynaklı olduğunu, bunların \%58'inin astım tanısı aldığını bildirmişlerdir. Gastrointestinal sisteme ait nedenler içinde gastroözefageal reflü sık görülüp gögüste yanma şeklinde karşımıza çıkmaktadır. Belirli gıdaların alımından sonra ağrının ortaya çıkması tanıda yardımcıdır ${ }^{2,16}$. Hastalarımızın \%8,9'unda başta gastroözofageal reflü olmak üzere gastrointestinal sisteme ait nedenler saptanmiştır.

Göğüs ağrısının nedenleri araştırılırken daha az görülen kollajen doku hastalıkları, gögüs dışındaki patolojilerden kaynaklanan ağrılar, meme büyümesi, cilt enfeksiyonları, malignite gibi bazı patolojilerin de akılda tutulması gerekmektedir1,13,17. Kardiyak kaynaklı gögüs ağrısı nadir olmasına karşı, beklenmedik hayati risklere neden olabileceğinden dolayı ayırıcı tanıda mutlaka göz önünde bulundurulmalıdır. Değerlendirmenin yapıldığı yere göre (acil poliklinik, genel poliklinik, çocuk kardiyoloji polikliniği) kardiyak etyoloji oranlarının değișmesi beklenmekle beraber çocuklardaki gögüs ağrıları içindeki sıklığı yaklaşık \%0-5 arasındadır ${ }^{5-7,12}$. Ülkemizde yapılan çalışmalarda ise kardiyak kaynaklı gögüs ağrısı sıklığı \%0,3-\%17 arasında saptanmıştır ${ }^{1,7,12,17 .}$ Ani başlangıçlı, uykudan uyandıran, egzersizle tetiklenen; solunum sıkıntısı, çarpıntı, baş dönmesi, bulantı, bayılma, terleme, solukluk, presenkop ve senkobun eşlik ettiği gögüs ağrıları, geçirilmiş kardiyovasküler cerrahi, ailede genç yaşta ani ölüm öyküsü bulunması gibi durumlarda hastalar kardiyak patolojiler açısından detaylı araştırılmalı ve çocuk kardiyoloji uzmanı tarafından da değerlendirilmelidir ${ }^{2}$. Aritmiler, miyokardiyal iskemi, perikardit, hipertrofik kardiyomiyopati, miyokardit, aort stenozu, mitral kapak prolapsusu göğüs ağrısı nedeni olabilen başlıca kalp hastalıklarıdır ${ }^{1,7,13}$. Çalışmamızda hastaların \%6,7'sinde kardiyak nedenler saptandı. Bu nedenler içinde de en sık saptanan patoloji mitral kapak prolapsusu idi. Mitral kapak prolapsusu olan hastalarda gögüs ağrısının nedeni konusunda tartışmalar olmakla birlikte prolapsusa bağlı olarak kordalarda gerilme sonucu oluşan iskeminin gögüs ağrısı nedeni olabileceği ileri sürülmüştür ${ }^{12}$.

Sonuç olarak göğüs ağrısı adölesan dönemde biraz daha fazla görülür. Gögüs ağrısını değerlendirirken hastaların büyük bölümünde organik bir neden olmadığı bilinmeli; bu yüzden de anamnez ve fizik muayeneye önem verilmelidir. Organik nedenler içinde hayatı tehdit edebilecek patoloji sıklığı oldukça az olup bunlar da genellikle kardiyak patolojilerdir. Kardiyak patoloji düşünülen hastalarda gerekli ileri incelemeler de yapılmalı ve çocuk kardiyoloji uzmanına danıșılmalıdır.

Çıkar Çatışması Beyanı: Yazarlar çıkar çatışması olmadığını bildirmişlerdir.

Finansal Destek: Bu çalışma her hangi bir fon tarafından desteklenmemiştir.

Declaration of Conflicting Interests: The authors declare that they have no conflict of interest.

Financial Disclosure: No financial support was received.

\section{KAYNAKLAR}

1. Sert A, Aypar E, Odabaş D, Gökçen C. Clinical characteristics and causes of chest pain in 380 children referred to a paediatric cardiology unit. Cardiology in the Young 2013; 23: 361-7.

2. Collins SA, Griksaitis MJ, Legg JP. 15-minute consultation: A structured approach to the assessment of chest pain in a child. Arch Dis Child Educ Pract Ed 2014; 99: 122-6.

3. Yeh TK, Yeh J. Chest Pain in Pediatrics. Pediatr Ann 2015; 44:e274-8. 
4. Kane DA, Fulton DR, Saleeb S, Zhou J, Lock JE, Geggel RL. Needles in Hay: Chest Pain as the Presenting Symptom in Children with Serious Underlying Cardiac Pathology. Congenit Heart Dis 2010; 5: 366-73.

5. Friedman KG, Alexander ME. Chest pain and syncope in children: a practical approach to the diagnosis of cardiac disease. J Pediatr 2013; 163: 896-901.

6. Saleeb SF, Li WY, Warren SZ, Lock JE. Effectiveness of screening for life-threatening chest pain in children. Pediatrics 2011; 128: 1062-8.

7. Güvenç O, Kaya F, Arslan D, Çimen D, Oran B. Göğüs Ağrısı Olan 441 Çocuk Hastanın Değerlendirilmesi/Evaluation of 441 Pediatric Patients with Chest Pain. Selçuk Tıp Derg 2014; 30: 159-61.

8. Ruigomez A, Rodriguez LA, Wallander MA, Johansson $\mathrm{S}$, Jones R. Chest pain in general practice: incidence, comorbidity and mortality. Fam Pract 2006; 23: 167 74.

9. Hanson CL, Hokanson JS. Etiology of chest pain inchildren and adolescents reffered to cardiology clinic. WMJ 2011; 11: 58-62.

10. Hambrook JT, Kimball TR, Khoury P, Cnota J. Disparities exist in the Emergency Department evaluation of pediatric chest pain. Congenit Heart Dis 2010; 5: 285-91.

11. Lin $\mathrm{CH}$, Lin WC, Ho YJ. Children with chest pain visiting the emergency department. Pediatr Neonatol 2008; 49: 26-9.
12.Alp H, Alp E. Çocuk Kardiyoloji Kliniğine Göğüs Ağrısı Nedeniyle Başvuran Çocukların Etiyolojik Değerlendirilmesi/Evaluation of the Etiology in Children with Chest Pain Who Admitted to Pediatric Cardiology Clinic. The Journal of Pediatric Research 2014; 1: 80-3.

13.Öztürk K, Çetin İİ, Ekici F, Kocabaş A, Şaylı TR. Göğüs Ağrısı Yakınması ile Başvuran Çocukların Etiyolojik Açıdan Değerlendirilmesi/Etiology of Chest Pain in Children. Turkish J Pediatr Dis 2015; 4: 248-53.

14. Rowe BH, Dulberg CS, Peterson RG, Vlad P, Li MM. Characteristics of children presenting with chest pain to a pediatric emergency department. CMAJ 1990; 143: 388-94.

15.Lipsitz JD, Gur M, Sonnet FM, et all. Psychopathology and disability in children with unexplained chest pain presenting to the pediatric emergency department. Pediatr Emerg Care 2010; 26: 830-6.

16. Cava JR, Sayger PL. Chest pain in children and adolescents. Pediatr Clin North Am 2004; 51: 155368.

17.Akın A, Bilici M, Söker M, Aldudak B, Meteroğlu F. Göğüs Ağrısı Çocuklardaki Malign Tümörlerin İlk Semptomu Olabilir: İki Olgu Sunumu/Chest Pain may be the First Symptom of Malignant Tumors in Children: Report of Two Cases. Dicle Med J 2016; 43: 162-5. 